\title{
Emerging HIV epidemic in north-eastern Ukraine: monitoring among different population groups
}

\author{
Anna Piddubna, Mykola Chemych \\ Sumy State University, \\ Department of Infectious Diseases and Epidemiology, Sumy, Ukraine
}

doi: 10.3396/IJIC.v9i3.023.13

\begin{abstract}
The distribution of HIV infection among different groups in Sumy region is were predominantly men in the age range of 18-29 years. Sumy region is relatively stable in relation to distribution of the epidemic. There is a trend involving women in the epidemic process, demonstrating an increase in sexual transmission and a high rate of infected prisoners. However, the intravenous drugs users (IDUs) remain at the highest risk of infection.
\end{abstract}

Key words: HIV Infections and Epidemiology; Epidemics; Ukraine

\section{Introduction}

HIV infection is a major social and health problem in low and middle income countries around the world. ${ }^{1,2}$ Taking Ukraine as a case study, the HIV epidemic has increased drastically every year. ${ }^{3}$ This has become one of the most important challenges of the healthcare sector in the country. ${ }^{4}$ In North-Eastern Ukraine the incidence of HIV/AIDS is increasing when compared to the data from previous years. As of 01/01/2013 1899 HIV-infected persons were identified of Sumy region, in which 465 were diagnosed with AIDS. The prevalence of HIV infection is estimated - to be 80.3 per 100 thousand population and the prevalence of AIDS to be 18.0 per 100 thousand population. Compared with 2005, the number of officially registered individuals with the initial diagnosis of HIV infection in 2011 increased 2.2 times and amounted to 203 people (17.4 per 100 thousand population). ${ }^{3}$ The incidence of AIDS has also increased from 4.3 per 100 thousand population in 2008 to 5.5 in 2009

\section{Corresponding Author}

Dr Anna Piddubna

Associate Professor/ Department of Infectious Diseases and Epidemiology, Sumy State University

Ukraine, 40021, Sumy, 15 Rokiv Peremogy str., 20

Email: tranki1@mail.ru 
(growth rate $27.7 \%$ ).,5 In 2011, 17 people died of AIDS related diseases, with a mortality rate of 1.4 per 100 thousand population. ${ }^{3}$

\section{Aim Of Study}

The aim of this study was to determine the prevalence of HIV infection among different populations of NorthEastern Ukraine and to identify the trend of epidemic process in this region.

\section{Materials And Methods}

Data was collected using epidemiological, serological and statistical research methods based on the Sumy Regional Centre for Disease Prevention and Control of HIV/AIDS (Sumy, Ukraine). A retrospective analysis of statistical data was conducted on the prevalence of HIV infections among injecting drug users (IDUs), individuals with sexually transmitted diseases (STDs), multiple sexual partners (MSPs), including men, who have sex with other men (MSM), blood donors, pregnant women, prisoners, patients screened for clinical indications (PSCI).

To assess the epidemiological trend in the groups listed above, the rate of newly diagnosed HIV infection per 100 thousand population in the region, the correlation between newly diagnosed HIV infected patients and the number of screening tests, and significant difference between the regional indices and national average data were considered.

\section{Results}

During the observation period of 2001-2011, the rate of HIV infections among injection drug users in Sumy region was below the national average (Table I), which may indicate a less favorable situation for the epidemic spread of HIV among this risk group. In 2011 the number of newly diagnosed HIV patients among IDUs per 100 thousand population in the region was 4.7 times lower than the national average.

Recording a downward trend of IDUs from the initial diagnosis of HIV infection indicates a decrease in the value of the epidemic of parenteral transmission in consequence to injection drug use. As seen in Table II, in 2001, Sumy region recorded the maximum number of IDUs with antibodies to HIV1/2. There is a decrease in the proportion of HIV transmission, from $62.6 \%$ in 2001 to $19.85 \%$ in 2010 . This may be attributed to a decrease in the total volume of testing in the region from 83.71 per 100 thousand population in 2001 to 71.32 in 2010.

\section{Table I. Rates of emerging HIV prevalence among different groups in Sumy region per 100 thousand population}

\begin{tabular}{|c|c|c|c|c|c|c|c|c|c|c|c|c|c|c|}
\hline \multirow[t]{2}{*}{ Year } & \multicolumn{3}{|c|}{ IDUs } & \multicolumn{2}{|l|}{ STDs } & MSPs & \multicolumn{2}{|c|}{ Prisoners } & \multicolumn{2}{|c|}{ Blood donors } & \multicolumn{2}{|c|}{$\begin{array}{r}\text { Pregnant } \\
\text { women }\end{array}$} & \multicolumn{2}{|r|}{ PSCI } \\
\hline & 1 & 2 & 1 & 2 & 1 & 2 & 1 & 2 & 1 & 2 & 1 & 2 & 1 & 2 \\
\hline 2001 & $6.28^{*}$ & 9,36 & $0.15^{*}$ & 1,39 & 0.23 & 0,39 & 1.38 & 1,19 & $0.31^{*}$ & 1,68 & $0.46^{*}$ & 2,74 & $1.23^{*}$ & 6,13 \\
\hline 2002 & $4.58^{*}$ & 9,83 & $0.47^{*}$ & 1,21 & $1.01^{*}$ & 0,33 & $1.32^{*}$ & 2,46 & $0.23^{*}$ & 1,91 & $0.86^{*}$ & 3,87 & $1.32^{*}$ & 6,22 \\
\hline 2003 & $3.78^{*}$ & 10,19 & $0.71 *$ & 1,44 & $0.95 *$ & 0,39 & $1.66^{*}$ & 3,37 & $0.08^{*}$ & 2,48 & $1.42 *$ & 5,36 & $0.39 *$ & 6,36 \\
\hline 2004 & $2.79 *$ & 10,62 & $0.4^{*}$ & 1,52 & 0.56 & 0,51 & $2.64^{*}$ & 6,92 & $0.08^{*}$ & 2,56 & $1.2^{*}$ & 6,88 & $0.64^{*}$ & 8,24 \\
\hline 2005 & $5.51^{*}$ & 10,24 & $0.24^{*}$ & 1,49 & 0.24 & 0,61 & $1.78^{*}$ & 5,94 & $0.41^{*}$ & 2,42 & $1.22 *$ & 6,26 & $1.46^{*}$ & 10,8 \\
\hline 2006 & $4.6^{*}$ & 11,7 & $0.25^{*}$ & 1,54 & 1.32 & 0,75 & $1.97^{*}$ & 5,53 & $0.25^{*}$ & 2,29 & $1.32^{*}$ & 6,88 & $2.38^{*}$ & 12,29 \\
\hline 2007 & $3.82 *$ & 11,03 & $0.33^{*}$ & 1,71 & 0.42 & 0,89 & $2.5^{*}$ & 5,83 & $0.42^{*}$ & 2,46 & $2.25^{*}$ & 7,84 & $3.58^{*}$ & 14,84 \\
\hline 2008 & $2.52 *$ & 10,74 & $0.34^{*}$ & 2,08 & $0.59 *$ & 1,49 & $2.78^{*}$ & 6,46 & $0.34^{*}$ & 2,47 & $2.27^{*}$ & 8,62 & $3.62 *$ & 16,62 \\
\hline 2009 & $2.28^{*}$ & 10,04 & $0.33^{*}$ & 1,79 & $0.33^{*}$ & 1,67 & $2.46^{*}$ & 6,29 & $0.5^{*}$ & 2,9 & $2.11^{*}$ & 7,91 & $3.38^{*}$ & 17,45 \\
\hline 2010 & $2.32^{*}$ & 8,94 & $0.34^{*}$ & 1,39 & $0.34^{*}$ & 1,89 & $2.64^{*}$ & 5,96 & $0.34^{*}$ & 2,57 & $2.22^{*}$ & 6,62 & $3.41^{*}$ & 16,61 \\
\hline 2011 & $2.5^{*}$ & 11,75 & $0.3^{*}$ & 1,59 & $0.3^{*}$ & 1,53 & $2.41^{*}$ & 5,38 & $0.43^{*}$ & 2,37 & $2.32^{*}$ & 8,58 & $3.36^{*}$ & 16,29 \\
\hline
\end{tabular}




\section{Table II. The share of persons with antibodies to HIV1/2 study groups in the total structure of HIV-infected persons in Sumy region}

\begin{tabular}{lrrrrrrrrrrr} 
Group & \multicolumn{10}{c}{ Year } \\
\cline { 2 - 12 } & $\mathbf{2 0 0 1}$ & $\mathbf{2 0 0 2}$ & $\mathbf{2 0 0 3}$ & $\mathbf{2 0 0 4}$ & $\mathbf{2 0 0 5}$ & $\mathbf{2 0 0 6}$ & $\mathbf{2 0 0 7}$ & $\mathbf{2 0 0 8}$ & $\mathbf{2 0 0 9}$ & $\mathbf{2 0 1 0}$ & $\mathbf{2 0 1 1}$ \\
\hline IDUs & 62.6 & $46.83^{*}$ & 42.11 & 33.65 & $50.75^{*}$ & $38.1^{*}$ & $28.75^{*}$ & $20.27^{*}$ & 20.0 & 19.85 & 21.32 \\
\hline STDs & 1.53 & 4.76 & 7.89 & 4.81 & 2.24 & 2.04 & 2.5 & 2.7 & 2.96 & 2.94 & 2.94 \\
\hline MSPs & 2.29 & $10.32^{*}$ & 10.53 & 6.73 & $2.24^{*}$ & $10.88^{*}$ & $3.12^{*}$ & 4.73 & 2.96 & 2.94 & 2.94 \\
\hline Prisoners & 13.74 & 13.49 & 18.42 & $31.73^{*}$ & $16.42^{*}$ & 16.33 & 18.75 & 22.3 & 21.48 & 22.79 & 20.59 \\
\hline Blood donors & 3.05 & 2.38 & 0.88 & 0.96 & 3.73 & 2.04 & 3.12 & 2.7 & 4.44 & 2.94 & 3.68 \\
\hline $\begin{array}{l}\text { Pregnant } \\
\text { women }\end{array}$ & 4.58 & 8.73 & $15.79^{*}$ & 14.43 & 11.19 & 10.88 & $16.88^{*}$ & 18.24 & 18.52 & 19.12 & 19.85 \\
\hline PSCI & 12.21 & 13.49 & $4.38^{*}$ & 7.69 & $13.43^{*}$ & $19.73^{*}$ & $26.88^{*}$ & 29.06 & 29.63 & 29.41 & 28.68 \\
\hline
\end{tabular}

* - significant difference of indexes compared to previous year $(p<0.05)$

Among persons with STDs in the region during 20032008, the number of tests performed significantly exceeded the national average by 1.1-1.6 times. Table I shows those with initial diagnosis of HIV infection for all years were below national average, which may indicate a low prevalence of HIV among this contingent in the region.

In 2011, the number of newly diagnosed HIV-infected patients with sexually transmitted diseases per 100 thousand people in Sumy was 5.3 times lower than the national average. In recent years, the spread of infection among this group may be characterized as relatively stable. From 2005 to 2008, the proportion of individuals with antibodies to HIV1/2 in STDs among the total number of identified HIV-positive individuals was at the same level and ranged 2.24-2.96 \% (Table II).

In the recorded volume of screening tests among individuals with MSPs and during years of observation the number of surveys among groups significantly exceeded the average in Ukraine 2.2 to 7.2 times. Despite this, the rate of newly diagnosed HIV-infected patients with MSPs in 2001, 2004-2007 was at national level, and only in 2002-2003 exceeded the national average by 2.4-3.1 times (Table I). In 2011, the number of newly diagnosed HIV-infected patients with MSPs per 100 thousand people in Sumy region was 5.1 times lower than the national average. Percentage of individuals with initial diagnosis of HIV infection in this risk group among the total number of identified HIV-positive people over the years of the study ranged from $2.24-10.88 \%$ (Table II).

The screening studies for antibodies to HIV1/2 among prisoners increased from 10.62 per 100 thousand population in 2005 to 23.73 in 2008, and it remains below the national average for the entire period of observation. The index of newly diagnosed HIVinfected persons in prison increased from 1.32 per 100 thousand population in 2002 to 2.78 in 2008, but was 2 to 3.3 times lower than that of the overall Ukraine percentage (Table I). This can be explained by the decreased (1.3-4.4) number of prisoners surveyed at 100 thousand population for the relevant national average value. Between the index of newly diagnosed HIV-infected individuals from prisons in Sumy region and the number of surveyed shows a direct strong correlation ( $r=0.74, p<0.05)$. Analysis of the proportion of different mechanisms for infection in the group of prisoners doesn't exist.

As can be seen from Table II, the proportion of persons from prisons among the total number of HIV-infected individuals increased by 2.3 times in 2004 compared to 2001 , but in subsequent years it has declined.

Newly diagnosed HIV-infected blood donors were significantly (5-32) times lower than the national average, which indicates a low prevalence of HIV among this population (Table I). In 2011, the number 


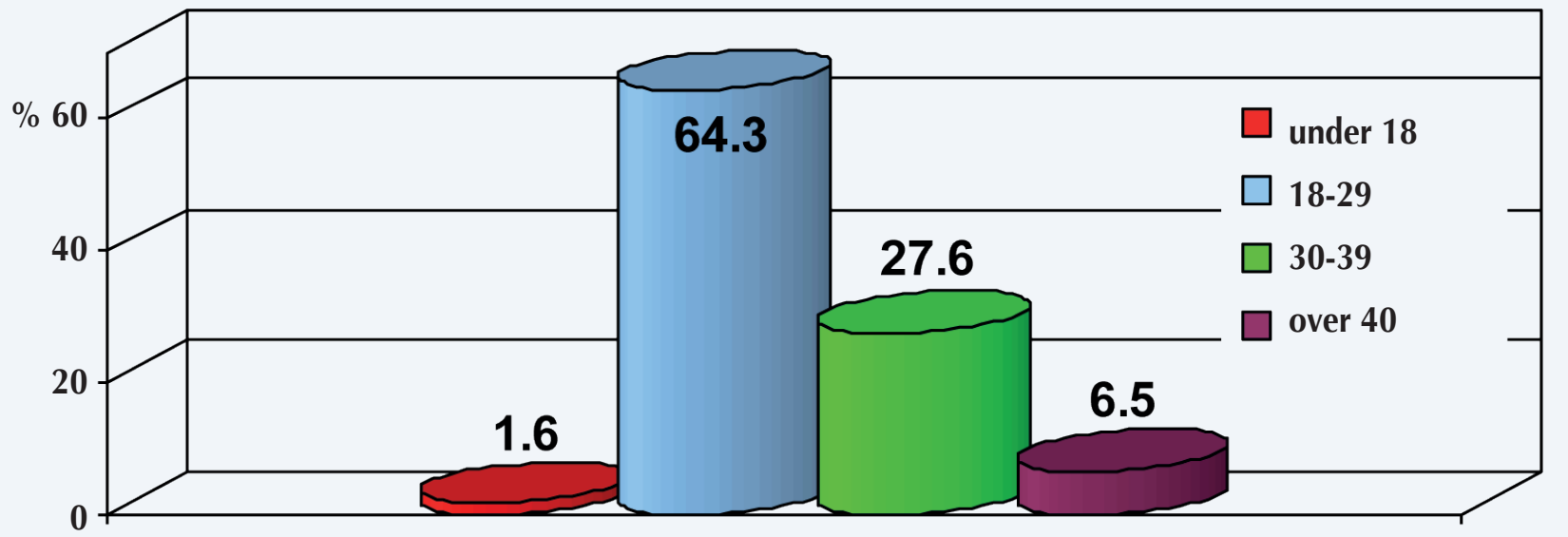

Figure 1. Age structure of HIV-infected in Sumy region

of newly diagnosed HIV-infected donors per 100 thousand population was 5.5 times less than the national average. However, against the background of decreasing numbers of blood donations, the rate of HIV-infected donors has a tendency to increase.

Among the newly diagnosed HIV-infected pregnant women the number was 3.5 to 6 times lower than the national average. For each year since 2001 there is a five-fold increase to a maximum in 2008 (Table I). In 2011, the number of newly diagnosed women with antibodies to HIV1/2 to 100 thousand people in the region was 3.7 times lower than the national average. Between the index of newly diagnosed HIV-infected pregnant women and the number of surveys (per 100 thousand population) was a direct strong correlation $(r=0.81, p<0.05)$. The proportion of HIV-infected pregnant women in the total number of HIV-positive individuals in 2006 increased by 1.7 times (Table II).
This indicates an increase in the spread of HIV among sexually active people in the region.

The number of HIV-positive patients who were examined for the presence of clinical signs of HIV infection has shown an increasing trend (Table II). The percentage of people with antibodies to HIV1/2 in this group among the total number of identified HIVpositive people has grown over time and was highest during the observation period in $2010-29.41 \%$. The index for newly identified HIV-infected people among the groups surveyed for clinical indications was less than the national average (Table I), but its growth is observed from the minimum value (0.39) in 2003 to a maximum (3.62) - in 2008. There was a direct correlation between the first indicator of HIV-infection and the number of surveys conducted. $\quad(r=0.93$, $\mathrm{p}<0.01)$.

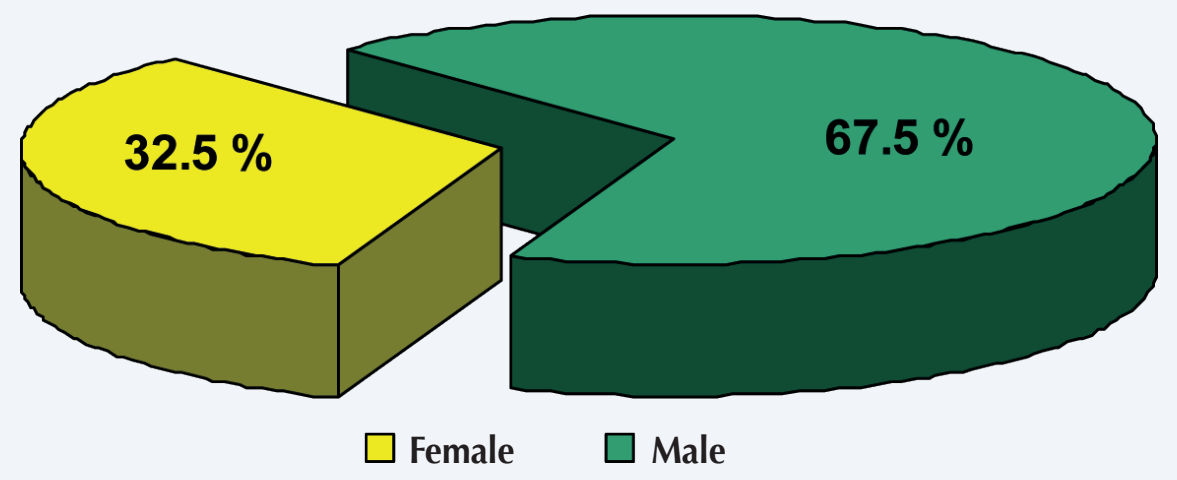

Figure 2. Sexual structure of HIV-infected in Sumy region 
On studying the age structure, revealed that the newly diagnosed HIV-infected group was dominated by people aged $18-29$ years $64.3 \%$ (Figure 1), followed by people in the $30-39$ age group $(27.6 \%)$. The number of individuals with antibodies to HIV $1 / 2$ from 18 to 40 years was $89.8 \%$, which exceeded the national average. $^{6}$

Males dominated HIV-infected persons in most of the groups studied (IDUs, prisoners, $\mathrm{PSCl}$, blood donors). Of groups with suspected HIV infection from sexual activity (STDs, MSPs) there was little predominance of females. In the region the percentage of HIV-infected males among the total number of HIV-positive was $67.5 \%$ and was significantly higher than the national average. The number of females was 1.5 times lower than the national average (Figure 2).

\section{Discussions}

Monitoring of HIV infection among different populations of Sumy region shows that, the NorthEastern part of Ukraine is relatively better off in terms of newly diagnosed HIV-infected persons, but there are prerequisites for the development of HIV infection among the general population. This situation can be attributed to several factors. Firstly, Sumy is a region with a low industrial potential, which promotes migration of young working population to other developed regions of the country with lower incomes, resulting in the preservation of the traditional way of life and a lower level of drug addiction. Despite a decline in the proportion of parenteral transmission, the largest proportion of HIV-infected persons during the years was recorded among this group. There was an increased rate of HIV infection among prisoners, despite limited screening for HIV infection in this group. Along with an increase in screening studies conducted in $\mathrm{PSCl}$, there was an increased rate of newly diagnosed HIV-positive persons in this group. There was an increase in the number of women with antibodies to HIV1/2 and the active involvement of the female population of Sumy region. Men aged 1829 years dominated among newly diagnosed HIVinfected people. Due to the increase in HIV-infected individuals in the population field, there needs to be focus on improved education to build a model of safe behavior among high risk groups, such as IDUs, prisoners, persons with MSPs and STDs.

These results indicate the need for an ongoing program of HIV preventive measures among the population.

\section{References}

1. UNAIDS. 2011 Global HIV/AIDS Response, Progress report Geneva: UNAIDS; 2011.

2. UNAIDS. 2010 Report on the Global AIDS Epidemic. Geneva: UNAIDS; 2010.

3. National AIDS Prevention Centre/Ministry of Health Information bulletin No 38. HIV infection in Ukraine in 2011. Kyiv: National AIDS Prevention Centre/Ministry of Health, 2012.

4. Alistar SS, Owens DK, Brandeau ML. Effectiveness and Cost Effectiveness of Expanding Harm Reduction and Antiretroviral Therapy in a Mixed HIV Epidemic: A Modeling Analysis for Ukraine. PloS Med 2011; 8(3): e1000423. http://dx.doi. org/10.1371/journal.pmed.1000423

5. National AIDS Prevention Centre/Ministry of Health Information bulletin No 31. HIV infection in Ukraine in 2008. Kyiv: National AIDS Prevention Centre/Ministry of Health, 2009.

6. National AIDS Prevention Centre/Ministry of Health Information bulletin No 33. HIV infection in Ukraine in 2009. Kyiv: National AIDS Prevention Centre/Ministry of Health, 2010. 